\title{
Death and caring for dying patients: exploring first-year nursing students' descriptive experiences
}

\author{
Kristina Ek, Lars Westin, Charlotte Prahl, Jane Österlind, Susann Strang, Ingrid Bergh, \\ Ingela Henoch, Kina Hammarlund
}

\begin{abstract}
n most health-care settings, nurses will encounter patients that are at the end of life and, consequently, need to be prepared for this demanding undertaking. It is the nurses' responsibility to establish meaningful relations with patients at the end of life (Browall et al, 2010). They focus on symptom control and quality of life, alleviate physical symptoms and offer psychological, social, and existential support for patients and their families (World Health Organization, 2014).

Providing good care at the end of life requires an internal commitment on the part of the nurse, as well as commitment from the professional caregivers (Mok and Chiu, 2004; Johnson and Smith, 2006). This commitment depends on the professionals' views and attitudes towards death and the dying individual they are caring for (Dunn et al, 2005). Within the team, it is often the nurse who is the primary caregiver of the patient approaching life's end. However, how well they manage this undertaking can be linked to their personal interest in caring for patients at the end of life (White et al, 2001).

Research demonstrates that nursing students have difficulties in dealing with death (Sadala and da Silva, 2009; Parry, 2011; Edo-Gual et al, 2014; Strang et al, 2014), and often feel emotionally unprepared to care for dying patients (White and Coyne, 2011). Nursing students are involved in caring for dying patients in different contexts where caregiving is required. Although caring for dying patients can be very rewarding (Charalambous and Kaite, 2013), it can also be emotionally demanding (Parry, 2011), and students often require support from clinical nurses. Nursing students can feel helpless, guilty and distressed while caring for dying patients (Deffner and Bell, 2005). Such emotional reactions limit the professional ability to care for dying patients and make it difficult for students to comprehend the emotional responses of the patients and their families (Cooper and Barnett, 2005).
\end{abstract}

Abstract
Aim: To describe first-year nursing students' experiences of
witnessing death and providing end-of-life care. Methods: This study
is part of a larger longitudinal project. Interviews ( $\mathrm{n}=17$ ) were
conducted with nursing students at the end of their first year of
education. To analyse the interviews (lived-experience descriptions), a
thematic analysis,'a search for meaning' (Van Manen, 1997) was applied.
Results: The results are presented within the framework of four
separate themes: (I) The thought of death is more frightening than the
actual experience, (2) Daring to approach the dying patient and
offering something of oneself, (3) The experience of not sufficing in the
face of death and (4) Being confronted with one's own feelings.
Conclusion: Nursing students require continuous support and
opportunity to reflect and discuss their experiences about caring for
dying patients and confronting death throughout the entirety of their
education. In addition, teachers and clinical supervisors need to give
support using reflective practice to help students to develop
confidence in their capacity for caring for dying patients.
Key words: Death End-of-life care Nursing education Nursing
students Experiences

In research carried out by Parry (2011) that focuses on nursing students' first encounter with a dying patient, the students felt that they lacked sufficient skills to properly cope with such situations. Furthermore, they were emotionally influenced by the situation and, in addition, by their mentors' attitude. Moreover, students felt that they lacked someone to speak with about the situation (Parry, 2011).

According to Cooper and Barnett (2005), the physical suffering of patients fills nursing students with anxiety about caring for people approaching the end of life. These feelings are especially evoked in cases where patients are of a younger age or in cases where patients die unexpectedly compared with deaths where patients are older and death is drawn out and anticipated. A final aspect of anxiety mentioned by the researchers is the anxiety experienced when students are forced to take care of the bodies of recently deceased patients.
Kristina Ek, RN, Senior Lecturer, Lars Westin, RN, Senior Lecturer, Charlotte Prahl, RN, Senior Lecturer, Jane Österlind, RN, Senior Lecturer Susann Strang, RN, Associated Professor, Ingrid Bergh, RN, Professor, Ingela Henoch, RN, Associated Professor Kina Hammarlund, RN, Senior Lecturer.

See Box 1 for full author details.

Corresponding author: Kristina Ek, University of Skövde, The School of Health and

Education, Sweden.

kristina.ek@his.se 


\section{Box I. Author details \\ Kristina Ek, RN, Senior Lecturer ' \\ Lars Westin, RN, Senior Lecturer \\ Charlotte PrahI, RN, Senior Lecturer ${ }^{2,3}$ \\ Jane Österlind, RN, Senior Lecturer ${ }^{2,3}$ \\ Susann Strang, RN,Associated Professor ${ }^{4,5}$ \\ Ingrid Bergh, RN, Professor ' \\ Ingela Henoch, RN,Associated Professor 5,6,2 \\ Kina Hammarlund, RN, Senior Lecturer ' \\ 1 University of Skövde, The School of Health and \\ Education, Skövde, Sweden \\ ${ }^{2}$ Ersta Sköndal University College and Ersta Hospital, \\ Palliative Research Centre, Stockholm, Sweden \\ ${ }^{3}$ Ersta Sköndal University College, Department of \\ Health Care Sciences, Stockholm, Sweden \\ ${ }^{4}$ Sahlgrenska Academy, University of Gothenburg, \\ Institute of Health and Care Sciences, Göteborg, \\ Sweden \\ ${ }^{5}$ Angered Local Hospital,Angered, Sweden \\ ${ }^{6}$ University of Gothenburg Centre for Person-Centred \\ Care (GPCC), Sahlgrenska Academy, University of \\ Gothenburg, Göteborg, Sweden}

Kink-Okoye and Arber (2013) explored second- and third-year nursing students' experiences of caring for patients with cancer at the end of life and described these as emotionally distressing and physically draining. The students evaded contact with these patients by using distancing and avoidance strategies. In cases where patients suffer from late-stage cancer, it is necessary for student nurses to feel supported and develop confidence in their capacity for care (Kink-Okoye and Arber, 2013). This means that student nurses must receive additional support, by means of reflective practice and sound mentoring within the clinical area (Kink-Okoye and Arber, 2013). Many nursing students have few, if any, experiences with death, but also have limited experience with nursing dying patients.

End-of-life care includes many complex aspects that require internal commitment and engagement, as well as creativity. Therefore, theoretical and clinical education plays a central role in preparing the students for this task. To be able to ascertain the type of training that is required, it is important to give expression to students' experiences of death as well as their involvement in caring for patients at the end of life. This article uses the definition for end-of-life care that divides the palliative phase into the early and late phase (Beck-Friis and Strang, 2005). The early phase can range from one to two years. The late phase is only from a few days up to one month. This article refers to the late palliative phase.
Aim

The purpose of this ongoing study is to describe first-year nursing students' experiences of death and caring for end-of-life patients.

\section{Method}

The interview study described within this article is part of a longitudinal project exploring the development of nursing students' attitudes toward:

The care of dying patients

The ultimate death of the patient in question. The full study will take place in intervals over the course of the students' education, i.e. at the start of their education; at the start of the second year and, finally, at the end of their studies.

\section{Participants}

In Sweden, to become a registered nurse $(\mathrm{RN})$, the students must complete a 3-year Bachelor of Science programme in nursing, which is required by the National Board of Health and Welfare. Initially, in this longitudinal project, students were recruited from three universities in Sweden, located in three different cities. All nursing students in their second term of studies were invited to participate (there were no exclusion criteria). Out of the 245 students that were invited, 222 chose to participate (189 women and 33 men).

In the first study, attitudes toward the care of dying patients and death were measured with the Frommelt Attitude toward Care of the Dying (FATCOD) Scale model (Frommelt, 1991). To achieve a deeper understanding of the phenomenon of nursing students' experiences of death and caring for dying patients, the 222 students were then asked to participate in an interview study. Out of these 222 students, 30 announced their interest. Finally, 17 students agreed to participate. This included nine students from one university, seven from another, and only one from the remaining university. All students were nearing the end of their first year of nursing education. The students were aged $20-40$ years and all were women born in Sweden.

\section{Data collection}

Data was collected via interviews during the course of the year in 2012 by six of the authors (KH, KE, LW, JÖ, CP and SS). A total of 17 interviews were performed at three separate universities in Sweden where the students were studying. Since a phenomenological method was used, the focus was on the students' experience of death and caring for dying patients. To obtain descriptions of the students' diverse experiences, an 
interview guide was implemented comprised of three areas:

O Students' feelings and readiness to encounter dying patients and their relatives

- Students' experiences of superior and inferior nursing with regard to caring for a dying patient

O Students' experiences of how the health professionals meet the needs of both the dying patient and their relatives.

In order to delve deeper into detail, elicit responses and advance the conversation constructively, probing questions were employed, such as: 'Can you tell me more about that?' and 'How did you feel in this situation?'. The interviews, which lasted 25-55 minutes, were recorded, transcribed verbatim into Swedish and finally translated into English.

\section{Analysis}

To analyse the interviews (lived-experience descriptions), a thematic analysis, 'a search for meaning' (Van Manen, 1997), was applied. A guiding principle in the analysis was to remain open to the students' narratives about their experiences of witnessing death and caring for dying patients and to create an understanding based on the nursing student's perspective.

The start of the analysis was performed using a holistic approach, in which the interviews were scrutinised several times in order to develop a reliable overall picture as well as to become genuinely acquainted with the content. Sentences and phrases in the texts, which corresponded with the aim of the study, were highlighted. Variations, as well as commonalities, in nursing students' experiences of witnessing death and caring for dying patients were sought. These were then organised into different structures of experience.

According to Van Manen (1997), structures of experiences can be described as the experiential structures that make the experience. These were then condensed into a coherent text and divided up into themes, which can be illustrated as knots in the web of the participating student's experiences. The whole process can be seen as a reiterative cycle of continually revisiting the interviews during the analysis. Three of the authors (KE, $\mathrm{KH}$ and LW) carried out the analysis and themes were discussed with the other co-authors.

The citations were chosen by the same three authors (KE, KH, and LW) and discussed with the other authors until a consensus was reached. A professional language reviewer, whose native language is English but who also speaks Swedish, then checked the translation.

\section{Ethical considerations}

The ethically sensitive aspect of this study was taken into account and it was recognised that the interviews conducted touch on a subject that could potentially create strong emotions. Student nurses' feelings were reflected on continually and the opportunity to discuss their emotional reactions was offered to all respondents upon completion of the interviews. None of the students requested this, however. Taking into account the sensitive nature of the study, approval by the Regional Ethics Committee was sought and later approved (Dnr 426-08, T 999-11). Approval was also obtained from the head of the departments for nurse education as well as from the student unions of all three universities. Students were given both verbal and written information detailing the study and all respondents offered their informed consent.

\section{Findings}

The results are presented in four different themes: The thought of death is more frightening than the actual experience

Daring to approach the dying patient and offering something of oneself

The experience of not sufficing in the face of death

Being confronted with one's own feelings.

\section{The thought of death is more} frightening than the actual experience

Student respondents expressed a fear of how they will experience encounters with the dying or recently deceased. They imagine that they enter a patient's room where there is a patient who is dying or who has recently passed away. This frightens them, as they experience this as an encounter with the unknown. This fear brings about a desire to come into contact with a patient at the end of life as early as possible during their education. They hope this will enable them to acquire knowledge about how the situation will affect them. As a result, students hope to gain practical training from the encounter and thereby eliminate their fearful fantasies and thoughts. Some student respondents were afraid to lose control and lose the ability to remain calm, thereby becoming incapable of providing the support that the patient and relatives require:

'Somewhere I fear how I will react. What if I become totally paralysed and just stand there and stare. It is probably not really the same thing, but imagine if I am not able to take action as I want to? Like I might totally fail' (Nursing student (NS) 1).
-Some students

were afraid to

lose the ability

to remain

calm,

becoming

incapable of

providing the

required

support to

patients and

relatives.' 
- Students fear

having too

many other

tasks to spend

adequate time

with the dying

patient.9
It appears to be the first encounter with death that fills the students with different emotions of fear and nervousness. To have assorted vivid images in their minds and to be unfamiliar with one's own reaction creates confusion and feelings that are difficult to deal with. Minutes before students are to see a dead person for the first time, thoughts and images pulsate through their minds. The knowledge that a dead person is lying in the adjacent room is an extremely unpleasant feeling. Respondents explain that they are more afraid of their own reaction than they are to see a dead human being for the first time. When they have finally confronted death and witness the lifeless body, they describe a picture of a person who is sleeping, where the experience is not nearly as difficult as they had imagined and fantasised it to be. After students have encountered recently deceased patients, they feel a new calm and explain further that they have been released from the fear that had gripped them:

'I had spoken with a nurse and explained that I was extremely frightened and didn't know how I would react when I experienced [seeing] death. So I got to go with her to the cold room where the patient was being stored and there was a sheet that was covering him so that I could not see the person, but it felt like all my fears were released' (NS 1).

One way for the students to deal with their fears regarding encounters with death is to approach it gradually. They explain that it can be a comfort to remain just outside the door, not entering the room where the dying patient is. Alternatively, they may remain for a time outside the door, feeling within themselves whether they are settled enough to move further. Another way is to wait until the following day before entering the room of the recently deceased patient. This can be done in the company of a nurse, allowing students the opportunity to inspect and feel the lifeless body in a peaceful and tranquil setting.

\section{Daring to approach the dying patient and offering something of oneself}

Nursing and interacting with the dying individual is experienced in various ways. On a personal level, it is experienced positively and feels enriching to come into contact with and develop a deeper relationship with the patient. There are different ways of making contact with dying patients who are seemingly unreachable. Several of the students claim that physical contact is an important aspect in the nursing of dying patients. Physical bodily contact is described as being sim- ple to use and is also experienced as meaningful for the dying individual. Physical contact can encompass everything from holding hands to rubbing the person with moisturising cream. One student describes her experiences when she sat beside a dying patient's bed giving the patient a drink while grasping the patient's hand:

'She looked at me briefly and when I leaned towards her she leaned towards me. When I held her hand during different instances she squeezed my hand. It felt as if I read her body language that she responded to the bodily contact that she received from me' (NS 4).

To be with a dying patient also entails being present in the room, both physically and emotionally, with thoughts completely focused on the situation. Several of the students interviewed emphasised the importance of showing the patient that $s /$ he is important 'here and now'. The intimacy that is experienced with a dying patient is mostly described in positive terms and gives students the opportunity to 'give of themselves'. However, owing to the gravity of the situation, the experience can also be distressing.

\section{The experience of not sufficing in the face of death}

Feelings of inadequacy coupled with the lack of time that can be allocated to the dying patient are thoughts that evoke strong emotions within the students. They feel that the dying individual should be surrounded by their family, friends and loved ones. If this is not the case, students fear having too many other tasks to perform so that they lack adequate time to spend with the dying patient. Their hope is then that the staff together will have time to create a situation for the patient that is conducive to optimal caregiving.

Cases where sudden and unexpected deaths occur can be especially difficult for students to experience. Students explain and provide examples of situations where a patient suddenly and unexpectedly falls ill and death appears imminent. When an unexpected death occurs, student respondents feel inadequate as a result of the presence of a sense that more could have been done for the dying individual. On the other hand, when students have the opportunity to adequately deal with the situation, the exact opposite can also be experienced and students feel that they are able to do something constructive for the patients.

For a nursing student who first gives care to a patient at the end of life and later sees the patient dead, this can be experienced as a very special sit- 
uation. The rapid transition of a living breathing human being to one that essentially ceases to exist can be a traumatic experience.

'I was there in the evening and soon after I had left the patient died. That is the closest that I have come to a dead body. That was the way that I felt, that he was no longer reachable and he was completely yellow and blue and we began to make preparations. It was an incredibly strange feeling, it is someone you have talked to and he had been able to say exactly how he wanted to have it and then he is suddenly just a body' (NS 10).

\section{Being confronted with one's own feelings}

The students talked about encountering and confronting their own emotions in both a positive and negative way-describing everything from difficult and trying situations to the meaning that is found in treating terminal patients. The students' experienced that patients maintain a high degree of wellbeing despite the pain and sickness when cared for at home and, particularly, when given the opportunity to express how they desire to spend the remaining days of their lives.

Another aspect that emerges from the students' narratives is that it is sometimes difficult for the students to know what the patients are thinking, since it is not always possible for the patients to express themselves with regard to how they want to spend their remaining days. As a result, students can become insecure about the patients' desires as they approach death. In addition, the students described becoming concerned about their intense involvement with the patient. When the patient expresses discontent, students have difficulty in understanding what it represents. This brings about negative feelings that they must confront:

'We are all different, we are all unique. I only hope that I have understanding for everyone. It happens that you are so involved with helping that you may not understand what is important for the person' (NS 8).

Additionally, the students describe situations where they feel doubtful about how the patient who expresses existential anguish in life's final stages wants to be cared for. They want to be able to care for patients as well as possible and be able to contribute something positive as death nears. Even if the care provided to the patient is adequate and the staff is able to truly attend to the patients, there are, nonetheless, distressing emotions to confront when patients express anguish. It is not the fact that the patient is approaching death that is disturbing; rather, it is the lack of knowledge about how to respond to a human being in despair: 'The most disturbing thing was her aura of
despair-to see that she was suffering' (NS 7).

At times, students felt moved when seeing patients during the remaining stages of their lives. These experiences result in students being forced to deal with their emotions in various ways. There are moments when it is difficult to confront one's own emotions. In these cases, students choose to back away for a short time so that they do not reveal their tears to patients and their families. Occasionally, students dare to reveal their sorrow, in a controlled manner. The emotions expressed by patients while receiving care awaken strong emotions that the students must confront. On some occasions, the patients' vulnerability and suffering results in an open display of emotion, which in turn makes it difficult for the students to conceal their sorrow:

'But it of course affects you and it will continue to do so for the rest of your life. On the other hand you might learn to deal with your emotions. But I think I did that then, I didn't start crying there and then. Instead I stepped aside' (NS 2).

Finally, the students discussed how it felt to follow the entire process from attending to the dying patient to viewing his or her dead body in the mortuary. The finality of leaving the recently deceased person in the cold room is experienced as especially distressing for the students. The whole process of witnessing a living being reduced to a corpse placed on a stretcher in a cold clinical environment fills the students with feelings of weariness and unworthiness.

\section{Discussion}

The results of this study show that first-year nursing students' experiences of caring for patients at the end of life and witnessing their eventual death affect students in several ways. Their narratives concern their own fears, reactions and feelings experienced when confronted with death. In addition, the anxiety of losing control and not being able to adequately support the patient and family are major concerns. The whole process involved in caring for a dying patient, building a relationship with the patient and finally witnessing the same patient lifeless as 'Caring for a
dying patient,
building a
relationship
and witnessing
the same
patient as a
corpse is
extremely
frightening. 
Students

expressed the

experience of

developing a

deeper

relationship

with the

patient during

end-of-life care

as positive and

enriching.9 a corpse lying in the morgue is extremely frightening and evokes strong emotions. According to Cooper and Barnett (2005), students describe many feelings such as sadness, vulnerability, helplessness and sympathy in their interactions with dying individuals. Such emotional reactions can limit health professionals' ability to care for dying patients effectively.

The greatest concerns and fears of the students seem to be how they will react when they are confronted with a deceased patient for the very first time. They appear to be more fearful of not having control over their own reactions than the actual experience of encountering a deceased human being. When they finally do find themselves in this position, however, their reaction is not at all as dramatic as they had supposed.

According to Sadala and da Silva (2009) and Parry (2011), nursing students struggle to deal with death and are not emotionally prepared to care for dying patients. Therefore, as pointed out by Kink-Okoye and Arber (2013), nursing students need support in order to develop confidence in their capacity to care for people approaching death. Previous research also shows that negative attitudes toward caring for dying patients is connected with two factors; age and a natural perception of death. In other words, students who were older and had a more natural perception of death had a less negative attitude towards caring for people who were dying compared with those who were younger and had a less natural perception of death. Other components that influence attitudes toward caring for dying patients, from the students' point of view, are fear of death and religiosity, which are factors that are reported to increase negative feelings (Iranmanesh et al, 2010).

On a personal level, the students expressed the experience of coming into contact and developing a deeper relationship with the patient during end-of-life care as positive and enriching. They explain that it is extremely meaningful for them to be able to be present, both physically and mentally, when encountering dying patients. Particularly in cases where the patient was unconscious, physical touch seems important in many cases when caring for a patient approaching death. To be totally focused on the patient is something the students believe is important, as well as showing empathy and commitment.

Mutto et al (2010) state that nursing students express a personal interest and experience positive feelings in assisting dying patients. Even if nursing students have an overall positive attitude concerning their experiences with dying patients and end-of-life care, to meet and care for a dying patient can be a demanding experience (Mutto et al, 2010). It is therefore important for nursing students to become aware of their own feelings and to receive the time and opportunity to reflect on these feelings during their education.

This is supported by Edo-Gual et al (2014), who reported that nursing students require training in end-of-life care, with special focus on training to manage their emotions. Previous research has demonstrated that when not provided with opportunities to discuss and reflect on their impressions, students in their final year of education perceive their education regarding terminally ill patients and end-of-life care as shallow compared with the perceptions of first-year students who did receive this opportunity (Mutto et al, 2010).

If students do not receive support in caring for dying patients throughout their education, they tend to shield themselves by avoiding emotional involvement with dying patients. The shielding process involves withdrawing from the care of the dying patient by reducing their relationship to the strictly basic matters at hand. Some students even attempt to avoid contact entirely with patients at the end of life (Mallory, 2003; Mutto et al, 2010). That health professionals are prepared to speak and interact with dying patients is important since open communication and relationship building has been found to be an essential attribute in patients' preparation for death (McLeod-Sordjan, 2014). Previous research shows that if students participate in educational programmes focusing on death and dying, participants generate a more positive attitude towards caring for end-of-life patients and their families than they would have otherwise (Frommelt, 2003).

Dunn et al (2005) claim that good palliative care requires an internal commitment and dedication to the task. This dedication depends on the professional's view and attitude towards death and the dying person that they are caring for. Nursing students have also acknowledged that encounters with death can be a learning experience, which could lead to personal growth. According to Edo-Gual et al (2014), it is important to work with designing adequate training programmes regarding end-of-life care in order to ensure that future nurses, above all, offer highquality care to patients and their families, while minimising the negative impact of encountering death and thereby preventing emotional fatigue.

\section{Limitations}

In order to cover all three universities, a group of students from each university was invited to par- 
ticipate. However, from one of these universities, only one student had the opportunity to participate in an interview. This may have affected the result; nevertheless, the interview was included to get a representation from all three universities. Another limitation in the study is that all the students were female and Swedish. It would have been better to study a mixed group of female and male students; unfortunately, there were very few male students enrolled in the nursing programmes. The results of this study should therefore be interpreted with this in mind.

\section{Future research}

There is a need for continuing research in this area. An interesting issue raised by the results of the present study is whether nursing students' experiences of death and caring for dying patients change over their 3-year education and after graduation. This highlights a potential area for further research.

\section{Conclusion}

The results of the present study show that nursing students want to contribute to positive endof-life care for dying patients. However, they also have a variety of complex thoughts and feelings surrounding end-of-life care. If nursing students experience difficulties in communication with the patient at the end of life, they can find it hard not knowing what is the best care for the patient. When having cared for a patient and the patient dies, this can also be traumatic for the student. Witnessing the transition of caring for a living human being, who then becomes a dead body can be experienced as emotionally arduous. Additionally, to see and take care of a dead body raises a lot of question for the students and they tend to be afraid of their own reactions. Once having been in the situation, however, the nursing students realise that to meet a dying patient and to see death is not as frightening as they had imagined and they gained valuable knowledge.

To be able to process such experiences, nursing students need continuous support and opportunity to reflect and discuss both end-of-life care and death throughout their education. This can be done, for example, through ongoing supervised reflection and drama to help students dare to approach demanding situations in safe surroundings, with support and guidance from experienced teachers and fellow students. IIPN

\section{Declaration of interests}

The authors have no conflicts of interest to declare.
Beck-Friis B, Strang P (2005) Palliative medicine. Liber, Lund

Browall M, Melin-Johansson C, Strang S, Danielson E, Henoch I (2010) Health care staff's opinions about existential issues among patients with cancer. Palliat Support Care 8(1): 59-68. doi: 10.1017/S147895150999071X

Charalambous A, Kaite C (2013) Undergraduate nursing students caring for cancer patients: hermeneutic phenomenological insights of their experiences. BMC Health Serv Res 13(63): 2-13. doi: 10.1186/1472-696313-63

Cooper J, Barnett M (2005) Aspects of caring for dying patients which cause anxiety to first year student nurses. Int J Palliat Nurs 11(8): 423-30

Deffner JM, Bell SK (2005) Nurses' death anxiety, comfort level during communication with patients and families regarding death, and exposure to communication education: a quantitative study. J Nurses Staff Dev 21(1): 1923

Dunn KS, Otten C, Stephens E (2005) Nursing experience and the care of dying patients. Oncol Nurs Forum 32(1):97-104

Edo-Gual M, Tomás-Sábado J, Bardallo-Porras D, Monforte-Royo C (2014) The impact of death and dying on nursing students: an explanatory model. J Clin Nurs doi: 10.1111/jocn.12602. [Epub ahead of print]

Frommelt KH (1991) The effects of death education on nurses' attitudes toward caring for terminally ill persons and their families. Am J Hosp Palliat Care 8(5): 37-43

Frommelt KH (2003) Attitudes toward care of the terminally ill: an educational intervention. Am J Hosp Palliat Care 20(1): 13-22

Iranmanesh S, Axelsson K, Häggström T, Sävenstedt $S$ (2010) Caring for dying people: attitudes among Iranian and Swedish nursing students. Indian I Palliat Care 16(3): 147-53. doi: 10.4103/0973-1075.73643

Johnston B, Smith LN (2006) Nurses' and patients' perceptions of expert palliative nursing care. J Adv Nurs 54(6): 700-9

King-Okoye M, Arber A (2014) 'It stays with me': the experiences of second- and third-year student nurses when caring for patients with cancer. Eur J Cancer Care (Engl) 23(4): 441-9. doi: 10.1111/ecc.12139. Epub 2013

Mallory JL (2003) The impact of a palliative care educational component on attitudes toward care of the dying in undergraduate nursing students. J Prof Nurs 19(5): 305-12

McLeod-Sordjan R (2014) Death preparedness: a concept analysis. J Adv Nurs 70(5): 1008-19. doi: 10.1111/ jan.12252. Epub 2013

Mok E, Chiu PC (2004) Nurse-patient relationships in palliative care. J Adv Nurs 48(5): 475-83

Mutto EM, Errázquin A, Rabhansl MM, Villar MJ (2010) Nursing education: the experience, attitudes, and impact of caring for dying patients by undergraduate Argentinian nursing students. J Palliat Med 13(12): 1445-50. doi: 10.1089/jpm.2010.0301

Parry M (2011) Student nurses' experience of their first death in clinical practice. Int J Palliat Nurs 17(9): 44651

Sadala ML, da Silva FM (2009) [Taking care of terminal patients: nursing students' perspective]. [Article in Portuguese]. Rev Esc Enferm USP 43(2): 287-94

Strang S, Bergh I, Ek K et al (2014) Swedish nursing students' reasoning about emotionally demanding issues in caring for dying patients. Int J Palliat Nurs 20(4): 194200

Van Manen M (1997) Researching Lived Expereince: Human science for an action sensitive pedagogy (2nd edn). Althouse Press, London

White KR, Coyne PJ, Patel UB (2001) Are nurses adequately prepared for end-of-life care? J Nurs Scholarsh 33(2): 147-51

World Health Organization (2014) Cancer. WHO Definition of Palliative Care. WHO, Geneva. http://tinyurl. com/5228js (accessed 30 September 2014)
When

students do

not receive

support in

caring for

dying patients

throughout

their

education, they

tend to shield

themselves by

avoiding

emotional

involvement

with the dying

patient.' 